\title{
Comparison of performance-related responses to an endurance running training between untrained men and women
}

\author{
Danilo Fernandes da Silva', Cecília Segabinazi Peserico², Fabiana Andrade Machado³ \\ 'School of Human Kinetics, Faculty of Health Sciences, University of Ottawa, Ottawa, ON, K1N6N5, Canadá. 2Department of Physical Education, State University of Maringá, Brazil. \\ ${ }^{3}$ Department of Physical Education, State University of Maringa, Brazil; Associate Post-graduate Program in Physical Education UEM/UEL, Department of Physical Education, State \\ University of Maringá-PR, Brazil; Post-graduate Program of Physiological Sciences, Department of Physiological Sciences, State University of Maringá-PR, Brazil.
}

doi: 10.18176/archmeddeporte.00021

Recibido: $15 / 04 / 2020$

Aceptado: 01/12/2020

\section{Summary}

Introduction: The adherence on endurance running events is increasing exponentially around the World in both previously untrained men and women, thus the incorporation of more appropriate and individualized training approaches are required. It is not known if male and female untrained runners differ in the responses to endurance running training on performancerelated variables.

Objective: We aimed to compare performance-related responses to an endurance running training program between untrained men and women.

Material and method: Sixteen participants ( 8 men and 8 women) were paired in the baseline by age, body mass index, and percentage in which time to complete $5 \mathrm{~km}\left(\mathrm{t}_{5 \mathrm{~km}}\right)$ represented from the average of best 50 runners $\mathrm{t}_{5 \mathrm{~km}}$ in the greatest regional race for each gender. They completed an 11 -week training protocol alternating high-intensity interval training and moderateintensity continuous running, three times per week, in a running track. In the week 1 and 11 of the protocol (baseline and post-training weeks), peak running velocity at treadmill $\left(\mathrm{V}_{\text {peak }}\right)$, time limit $\left(\mathrm{t}_{\text {lim }}\right)$ at $100 \% \mathrm{~V}_{\text {peak }}, \mathrm{t}_{5 \mathrm{~km}^{\prime}}$, and the index rMSSD of heart rate variability (HRV) were measured for cardiac autonomic function. Baseline gender-differences were accounted in the analysis. Results: Male and female significantly improved $\mathrm{V}_{\text {peak }}\left(9.4 \pm 1.7 \%\right.$ and $7.2 \pm 1.7 \%$, respectively) and $\mathrm{t}_{5 \mathrm{~km}}(-13.0 \pm 1.8 \%$ for both), and no gender-related differences for the adaptations in these two variables were observed. The $\mathrm{t}_{\lim }$ at $100 \% \mathrm{~V}_{\text {peak }}$ and rMSSD did not change across the training period in both groups. Percentage of change for men was "moderately" higher than for women for rMSSD ( $33.4 \pm 40.7 \%$ vs. $13.9 \pm 21.4 \%)$, although statistically non-significant.

Key words: Conclusion: Men and women responses to training were similar with regards to their running performance and cardiac auAthletic performance. Exercise. tonomic function. With regards to practical application, $V_{\text {eak }}$ and its $t_{\text {lim }}$ can be applied in exercise settings for the prescription Running. Gender. of moderate- to high-intensity running training with similar benefits regardless of the biological gender.

\section{Comparación de respuestas relacionadas con el rendimiento a un entrena- miento de carrera de resistencia entre hombres y mujeres no entrenados}

\section{Resumen}

Introducción: La adherencia a los eventos de carreras de resistencia está aumentando exponencialmente en el mundo entre hombres y mujeres no entrenados, y por eso es necesaria la incorporación de un entrenamiento individualizado y apropiado. No se sabe si los hombres y mujeres desentrenados en carrera difieren en las respuestas al entrenamiento de carrera de resistencia en relación a las variables relacionadas con el rendimiento.

Objetivo: Nuestro objetivo fue comparar las respuestas del rendimiento durante un programa de entrenamiento de carrera de resistencia entre hombres y mujeres no entrenados.

Material y método: Dieciséis participantes (8 hombres y 8 mujeres) fueron emparejados en la línea de base por edad, índice de masa corporal y porcentaje del tiempo para completar los $5 \mathrm{~km}\left(\mathrm{t}_{5 \mathrm{~km}}\right)$ representados por el promedio de los $\mathrm{t}_{5 \mathrm{~km}}$ de los 50 mejores corredores obtenidos en las mejores carreras regionales (para cada género). Los participantes completaron un protocolo de entrenamiento de 11 semanas alternando entrenamiento de intervalos de alta intensidad con entrenamiento continuo de intensidad moderada, tres veces por semana, en una pista de atletismo. En las semanas 1 y 11 del protocolo (línea de base y semana posterior al entrenamiento), se midieron la velocidad máxima de carrera en la cinta $\left(V_{\text {peak }}\right)$, el tiempo límite $\left(\mathrm{t}_{\mathrm{lim}}\right)$ en $\mathrm{V}_{\text {peak' }} \mathrm{t}_{5 \mathrm{~km}}$ y el índice rMSSD de la variabilidad de la frecuencia cardíaca (VFC) para la función cardíaca autónoma. En los análisis se consideraron las diferencias entre géneros en la línea de base.

Resultados: Hombres y mujeres mejoraron significativamente la $V_{\text {peak }}\left(9,4 \pm 1,7 \%\right.$ y $7,2 \pm 1,7 \%$, respectivamente) y el $t_{5 k m}(-13,0$ $\pm 1,8 \%$ para ambos), y se observaron diferencias relacionadas con el género para las adaptaciones en estas dos variables. El $t_{\text {lim }}$ en $V_{\text {peak }}$ y el rMSSD no han cambiado durante el período de entrenamiento en ambos grupos. El porcentaje de cambio en los hombres fue moderadamente superior al de las mujeres para la rMSSD (33,4 $\pm 40,7 \%$ vs. 13,9 $\pm 21,4 \%)$, aunque no fue significantemente diferente.

Conclusión: Las respuestas de hombres y mujeres al entrenamiento fueron similares considerando el rendimiento de carrera

Palabras clave:

Desempeño atlético. Ejercicio. Carrera. Géneros.

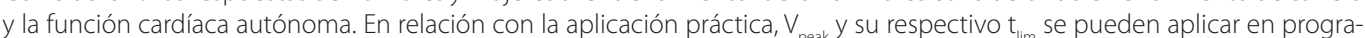
maciones de ejercicio para prescribir intensidades de entrenamiento de carrera con intensidades moderadas a altas y con beneficios similares, independientemente del género.

Correspondencia: Cecília Segabinazi Peserico

E-mail: ceciliapeserico@gmail.com 


\section{Introduction}

Running is one of the most common types of endurance exercise and the popularity of this activity has increased exponentially in the last few decades ${ }^{1,2}$, which can be seen by the number of finishers in the 20 largest road races in the world that doubled in an 11-year period (from $\approx 866.000$ to 1.600 .000 finishers) 3 . Both men and women have increased their adherence to endurance running events in recreational level with participation numbers never seen before ${ }^{4,5}$. The higher rates of adherence are followed by significant improvements in performance, as the average finishing time of the top 100 and 1000 men and women in traditional 10-km road running races has previously shown to significantly decrease annually4.

The improvements in running performance are likely related to greater engagement in endurance training routines as well as the incorporation of more appropriate and individualized training approaches that increase the magnitude of benefits (e.g., high-intensity interval trainings and their potential variation and strength muscular training) $)^{6-10}$. This training approach is capable of increasing markers of aerobic fitness (e.g., $\left.\dot{V}_{2 \max }\right)^{11}$, which are expected to reduce risk of all-cause mortality and cardiovascular mortality ${ }^{12}$. Different running training programs have been developed ${ }^{13-16}$ and they usually combine moderate-intensity continuous training (MICT) and high-intensity interval training (HIIT)" More interestingly, these training regimens have been proven effective not only for the highly athletic population, but also in untrained and moderately-trained ones s,13,17. $^{\text {. }}$

HIIT seems to contribute to improve aerobic energy metabolism and promote neuromuscular, cardiovascular and respiratory changes ${ }^{8}$ that will benefit physiological markers, such as cardiac autonomic function and aerobic power ${ }^{18}$, as well as endurance performance ${ }^{17}$. However, women may present physiological disadvantages when compared to men, such as lower systolic volume and cardiac mass, lower lungs, and are more prone to arterial desaturation when performing high-intensity exercise ${ }^{19,20}$. Additionally, women present smaller muscle cross-sectional area $^{21}$ and lower glycolysis rates in type I muscle fibers ${ }^{22}$, which result in lower blood lactate concentrations during sprint exercise ${ }^{23}$. On the other hand, women showed higher aerobic participation in sprint exercise than men ${ }^{8}$.

Together, these evidences suggest that men and women may metabolically and muscularly differ in their responses to sprint/HIIT ${ }^{8,22}$, and these differences could play a role on physiological markers of aerobic fitness (e.g., $\dot{\mathrm{V}} \mathrm{O}_{2 \max }$ ). However, a few studies with untrained sedentary populations showed that men and women improved $\dot{\mathrm{V}} \mathrm{O}_{2 \max }$ similarly after aerobic training with HIIT incorporated ${ }^{11,24}$. Despite these interesting findings, to the best of our knowledge, differences between male and female in the responses to endurance running training on performancerelated variables (e.g., time trials, the maximal velocity at incremental running test) are poorly understood ${ }^{8}$. Investigations on this topic are further required in a protocol combining HIIT with MICT, given these two strategies are very likely the most popular ones adopted in endurance exercise setting $\mathrm{s}^{25}$ and have been shown to be capable of improving $5-\mathrm{km}$ running performance ${ }^{26}$. A comparison between men and women after this type of aerobic training could improve the individualization of training regimens ${ }^{24}$.
Thus, this study aimed to compare performance-related responses $\left(\left[\mathrm{V}_{\text {peak }}\right],\left[\mathrm{t}_{\mathrm{lim}}\right],\left[\mathrm{t}_{5 \mathrm{~km}}\right]\right.$ and $\left.[\mathrm{HRV}]\right)$ to an endurance running training program between untrained men and women. The training sessions consisted of MICT and HIIT. We hypothesized that there are no differences in endurance running training changes on performance-related markers between males and females, considering that changes in $\dot{\mathrm{VO}}_{2 \max }$ did not differ after aerobic training between genders ${ }^{1,24}$.

\section{Material and method}

\section{Participants}

The study was based on a quasi-experimental pre-post test design. Firstly, the recruitment of participants was carried out by disseminating the study through electronic means and direct contact. Thus, sixteen untrained participants ( 8 male and 8 female) aged between 20 and 35 years participate in this study. The inclusion criteria were to be an untrained who had never engaged in systematic running training program with a coach and individualized running training prescription and be aged between 20 to 35 years old. With regards to the exclusion criteria, the individuals were excluded if they reported to use regular pharmacological agents or nutritional supplements; smoker, diabetic, hypertensive, asthmatic and/or present any cardiovascular disease; body mass index $(\mathrm{BMI}) \geq 30 \mathrm{~kg} \cdot \mathrm{m}^{-2}$; and were engaged in other systematic exercise training. Prior to testing, all participants signed the informed consent form to participate in the study. All procedures and test protocols were explained individually for each participant, and were in accordance with the Declaration of Helsinki. The protocol was approved by the Local Human Research Ethics Committee (\#623.581/2014; \#409.162/2013) and appropriate standards for human experimentation have been followed.

Men and women were matched in the baseline for the following characteristics: age, $\mathrm{BMI}$, and percentage in which time to complete 5 $\mathrm{km}\left(\mathrm{t}_{5 \mathrm{~km}}\right)$ represented from the average of best 50 runners $t_{5 \mathrm{~km}}$ in the greatest regional race for each gender.

\section{Experimental design}

This was an 11-week protocol with eight weeks of endurance running training (from week 2-5 and week 7-10) and three weeks of exercise testing (week 1 for baseline tests, week 6 to update exercise prescription and week 11 for post-training tests). The training program consisted of sessions with MICT and HIIT. Prior to assessments, it was performed a resting and maximal exercise electrocardiogram and echocardiogram by a cardiologist to follow local recommendations prior to engaging in high-intensity exercise training. Both men and women performed a continuous incremental test under laboratory conditions (temperature $=20-22^{\circ} \mathrm{C}$ and relative humidity $=50-60 \%$ ) on a motorized treadmill (Inbramed Super ATL ${ }^{\oplus}$, Porto Alegre, Brazil) to determine $\mathrm{V}_{\text {peak. }}$. The second test consisted on a time limit $\left(\mathrm{t}_{\mathrm{lim}}\right)$ at $100 \% \mathrm{~V}_{\text {peak' }}$ and the third trial was a 5 -km running performance performed in outdoor running track. These evaluations were performed in a maximum period of seven days and separated from each other by $48 \mathrm{~h}$ to ensure the recovery of the participants ${ }^{27}$. Furthermore, cardiac autonomic function by HRV was evaluated 
pre- and post-training for all participants. Participants were instructed to attend the testing sessions well rested, nourished, hydrated and wearing comfortable clothing. Furthermore, they were also instructed to avoid eating $2 \mathrm{~h}$ before the tests, to abstain from caffeine and alcohol, and to refrain from strenuous exercise for $24 \mathrm{~h}$ before testing.

After baseline evaluations men and women performed the exact same standardized training protocol. Assessments and training protocol are described below.

\section{Assessments}

\section{Cardiac autonomic function evaluated by heart rate variability (HRV)}

The rate-to-rate $(R-R)$ intervals were monitored for 5 minutes, starting in seated position (2-min) and then in standing position (3-min); only the 3 minutes in the standing position were considered in the analysis ${ }^{28}$. We chose this position to avoid possible saturation of HRV, expressed as unchanged or even decreased HRV despite increased cardiac vagal outflow, which is susceptible at low heart rate (HR) levels ${ }^{29}$. Moreover, this position seems to be more suitable to long-term changes on HRV (i.e., 24 and 48 h), favoring HRV application in exercise training setting $s^{27}$. Participants were instructed to remain quiet, with eyes open, and to breathe spontaneously over the data acquisition period $^{30,31}$. We used a HR monitor (Polar ${ }^{\oplus}$, RS800cx, Kempele, Finland) previously validated for this purpose ${ }^{32}$. Ectopic, missed or aberrant values were identified and excluded ${ }^{33}$. R-R intervals data was downloaded the software (Polar Pro Trainer ${ }^{\circledR}$ ) and expressed in milliseconds to be analyzed by Kubios ${ }^{\oplus} \mathrm{HRV}$ analysis software (Department of Applied Physics, University of Eastern Finland, Kuopio, Finland). The R-R intervals were analyzed using the time-domain index square root of the mean of the squares of successive R-R intervals differences (rMSSD) 13,29,34.

\section{Peak running velocity (Vpeak) at treadmill}

The $V_{\text {peak }}$ was measured at week 1 and week 11 of the protocol to assess training effects and at week 6 to update prescribed training intensities. After warming-up walking for 3 min at $6 \mathrm{~km} \cdot \mathrm{h}^{-1}$, the protocol initiated with a treadmill velocity of $8 \mathrm{~km} \cdot \mathrm{h}^{-1}$, followed by an increase of $1 \mathrm{~km} \cdot \mathrm{h}^{-1}$ at each successive 3 -min stage until volitional exhaustion (i.e., participant was unable to continue running ${ }^{35,36}$ and when the two the following criteria were met: (1) maximum $\mathrm{HR}\left(\mathrm{HR}_{\max }\right) \geq 100 \%$ of endurance-trained age-predicted $\mathrm{HR}_{\max }$ using the age-based "206- 0.7 $\times$ age $^{\prime \prime}$ equation ${ }^{37}$ and (2) maximum RPE (RPE $\left.{ }_{\text {max }}\right) \geq 18$ in the 6-20 Borg scale ${ }^{38}$.The incline gradient was set at $1 \%{ }^{39}$. Consistently across each trial, participants were verbally encouraged, to invest maximum effort.

Before testing, participants were familiarized with the 6-20 Borg scale $^{38}$, which was used to determine the rating of perceived exertion (RPE) during the last 15 seconds of each stage and at perceived exhaustion. The highest RPE value was considered the maximal RPE (RPE ${ }_{\text {max }}$ ). HR was also measured at the last 15 seconds of each stage of the tests (Polar ${ }^{\circledast}$ RS800sd, Kempele, Finland) and $\mathrm{HR}_{\max }$ was defined as the highest $H R$ value recorded during the test.

The $V_{\text {peak }}$ was defined as the velocity of the last complete stage added to the multiplication of the velocity increment by the completed fraction of the incomplete stage, calculated according to the equation ${ }^{40}$ :
$V_{\text {peak }}=V_{\text {complete }}+(\operatorname{Inc} \times t / T)$, in which ' $V_{\text {complete }}$ is the running velocity of the last complete stage, Inc the velocity increment (i.e., $1 \mathrm{~km} \cdot \mathrm{h}^{-1}$ ), ' $\mathrm{t}^{\prime}$ the number of seconds sustained during the incomplete stage, and ' $T$ ' the number of seconds required to complete a stage (i.e., 180 s).

\section{Time limit $\left(t_{\text {lim }}\right)$ at $V_{\text {peak }}$}

After a 15 -min warm-up at $60 \% \mathrm{~V}_{\text {peak' }}$ the running velocity in the treadmill was increased (over 6 seconds) to the individual's $V_{\text {peak }}{ }^{41}$. The incline gradient was set at $1 \%{ }^{39}$ and participants were also encouraged to provide their maximal effort. The result obtained in the $t_{\lim }$ test was the test duration ( $\mathrm{min}$ ) without considering the warm-up. This variable was measured at week 1, 6 and 11 of the protocol to assess training effects and for the prescription of the duration of the series and intervals during HIIT sessions.

\section{5-km running performance}

It was completed as a field test to verify the time to complete a $5-k m$ running performance $\left(t_{5 k m}\right)$. This took place on a 400-m running track after 10 minutes of warm-up. The warm-up included 5-min jogging at a self-selected intensity and 5-min stretching.

\section{Diary of symptoms related to pre-menstrual syndrome (PMS)}

Women were instructed to provide information daily regarding emotional and physical symptoms related to PMS that were based on the criteria established by the American College of Obstetricians and Gynecologists ${ }^{42}$. Given that the diagnosis of PMS requires a long follow-up period to ensure the symptoms are consistently present (e.g., at least three cycles in a row) ${ }^{42}$, we classified women as presenting or not presenting symptoms related to PMS. In brief, when the subject presented a combination of at least one emotional symptom and one physical symptom in the five days prior to menstruation, that were not observed in the follicular period (from the sixth to the tenth day of the menstrual cycle), PMS was noted ${ }^{42}$.

\section{Endurance running training}

Training sessions were performed on a 400-m running track during the afternoon and evening due to the availability of the participants on Mondays, Wednesdays, and Fridays. If for any reason they missed a training session, they were re-scheduled for another weekday (usually Tuesday or Thursday) in order to perform at least $90 \%$ of the training sessions (i.e., at least 22 of the 24 training sessions prescribed). Participants were asked to do their training and subsequently testing at a similar time each day to avoid circadian cycle influence.

Training sessions consisted of MICT and HIIT. MICT and HIIT were both performed in the first (weeks 2 to 5) and last (weeks 7 to 10) training weeks. The MICT and HIIT were prescribed based on of $\mathrm{V}_{\text {peak }}$ and $\mathrm{t}_{\lim }$ at $100 \% \mathrm{~V}_{\text {peak }}$ determined during pre-training (week 1) and the exercise intensity was readjusted at week 6 (Table 1) 11,24. Training sessions were preceded by a 15 min warm-up, with 5 min of low self-selected intensity running, 5 min of stretching exercises, and 5 min of running at $60 \% \mathrm{~V}_{\text {peak }}$. After each session, participants had 10-15 minutes of cool-down. In total, both groups of participants performed 24 training 
Table 1. MICT and HIIT used during training sessions for both groups.

\begin{tabular}{ll}
\hline & $\mathbf{1}^{\text {st }}$ four weeks of training \\
MICT & $30 \pm 2.5$ minutes at $75 \pm 4 \%$ of $\mathrm{V}_{\text {peak }}$ \\
HIIT & $X^{a}$ series at $100 \pm 2 \%$ of $\mathrm{V}_{\text {peak }}$ with duration of \\
& $60 \%$ of $\mathrm{t}_{\text {lim }}$ and the same interval $(1: 1)$ \\
\hline & $\mathbf{2}^{\text {nd }}$ four weeks of training \\
MICT & $40 \pm 2.5$ minutes at $75 \pm 4 \%$ of $\mathrm{V}_{\text {peak }}$ \\
HIIT & $X^{a}$ series a $100 \pm 2 \%$ of $\mathrm{V}_{\text {peak }}$ with duration of \\
& $60 \%$ of $\mathrm{t}_{\text {lim }}$ and the same interval (1:1) \\
\hline
\end{tabular}

The number of series of each participant was adjusted for a duration of $30 \pm 2.5$ minutes (in the 1 st four weeks of training) and $40 \pm 2.5$ minutes (in the 2 nd four weeks of training).

HIIT: High intensity interval training; MICT: moderate-intensity continuous training.

sessions on non-consecutive days over a period of eight weeks (weeks 2-5 and weeks 7-10). They completed eight weeks of training with MICT and HIIT training every other day. All training sessions were monitored by session-RPE and training load was quantified by multiplying the whole RPE using the 10-point scale (CR-10) by its duration (min $)^{43}$.

\section{Statistical analysis}

The Statistical Package for the Social Sciences 17.0 software (SPSS Inc., United States) was used in the analysis. Data were presented as means \pm standard deviations (SD). Normality was tested with the Shapiro-Wilk test. Group comparisons at baseline were performed $t$ tests for independent samples according to normality test results. The training adaptations (i.e., Week 1 vs. Week 11) were assessed using paired t-test for each gender. Gender differences in the variation between week 1 vs. week 11 were tested with univariate ANOVA and ANCOVA (controlling by the baseline values when baseline between-group significant differences were observed). Statistical significance was set at $P<0.05$. In addition, effect size (ES) ${ }^{44}$ and confidence intervals $(\mathrm{Cl})$ were used to determine the magnitudes of differences between groups (Hedges' g) for training adaptations. The threshold values for ES were: $<0.2$ (trivial), 0.2 to $<0.6$ (small), 0.6 to $<1.2$ (moderate), $\geq 1.2$ (large) ${ }^{45}$.

\section{Results}

\section{Baseline comparison between men and women}

With regards to the matching parameters for men vs. women, no differences were found to age (male: $26.6 \pm 5.0$ years; female: $26.3 \pm 3.2$ years; $P=0.853$ ), BMI (male: $25.8 \pm 3.0 \mathrm{~kg} \cdot \mathrm{m}^{-2}$; female: $22.8 \pm 4.8 \mathrm{~kg} \cdot \mathrm{m}^{-2}$; $P=0.157$ ) or percentage in which $t_{5 \mathrm{~km}}$ represented from the average of best 50 runners $_{5 \mathrm{~km}}$ in the greatest regional race for each gender (male: $148.9 \pm 27.7 \%$; female: $160.7 \pm 24.9 \% ; P=0.385$ ).

Training loads measured by session-RPE were not different between groups for both MICT (male: $299 \pm 113.4 \mathrm{AU}$; female: $280.8 \pm 68.5 \mathrm{AU}$; $P=0.703$ ) and HIIT (male: $345.6 \pm 101.0 \mathrm{AU}$; female: $331.0 \pm 73.0 \mathrm{AU}$; $P=0.747$ ). The cardiac autonomic function (male rMSSD: $21.9 \pm 6.2 \mathrm{~ms}$; female rMSSD: $24.5 \pm 10.3 \mathrm{~ms} ; P=0.563$ ) and $\mathrm{t}_{\text {lim }}$ at $\mathrm{V}_{\text {peak }}$ (male: $6.3 \pm 0.7$ min; female: $5.2 \pm 1.3 \mathrm{~min} ; P=0.054$ ) were also not different between genders. However, the $t_{5 \mathrm{~km}}$ (male: $28.1 \pm 3.0$ min; female: $36.9 \pm 5.7$ min; $P=0.002$ ) presented higher values in women while $V_{\text {peak }}$ (male: 13.2 $\pm 0.9 \mathrm{~km} \cdot \mathrm{h}^{-1}$; female: $36.9 \pm 5.7 \mathrm{~km} \cdot h^{-1} ; P=0.001$ ) was higher for men.

\section{Responses to endurance running training}

Male and female significantly improved $\mathrm{V}_{\text {peak }}$ (male: $9.4 \pm 1.7 \%$; female: $7.2 \pm 1.7 \%$ ) and $t_{5 \mathrm{~km}}$ (men: $-13.0 \pm 1.8 \%$; female: $-13.3 \pm 1.8 \%$ ). No gender-related differences for the adaptations in these two variables were observed.

The $\mathrm{t}_{\text {lim }}$ at $100 \% \mathrm{~V}_{\text {peak }}$ and $\mathrm{rMSSD}$ did not change across the training period in either men and women. Percentage of change for men was "moderately" higher than for women for rMSSD, although not significantly different (confidence intervals crossing " 0 " for both ANOVA and ES). Mean and standard deviation as well as inferential analyses are presented in Table 2.

\section{Symptoms related to pre-menstrual syndrome (PMS)}

The results concerning the frequency of women who presented symptoms related to PMS, from the eight women assessed, three presented emotional and physical symptoms during pre-menstrual phase

Table 2. Peak running velocity $\left(\mathrm{V}_{\text {peak }}\right)$, time limit at peak running velocity $\left(\mathrm{t}_{\text {lim }}\right.$ at $\left.100 \% \mathrm{~V}_{\text {peak }}\right)$, time to complete the $5 \mathrm{~km}\left(\mathrm{t}_{5 \mathrm{~km}}\right)$, and square root of the mean of the squares of successive R-R intervals (rMSSD) differences pre and post endurance running training program in male and female.

\begin{tabular}{|c|c|c|c|c|c|c|c|c|}
\hline \multirow[b]{2}{*}{ Variable } & \multicolumn{2}{|c|}{ Male $(\mathbf{n}=\mathbf{8})$} & \multirow[b]{2}{*}{$\begin{array}{l}\text { Variation } \\
(\%, 1 \times 11)\end{array}$} & \multicolumn{2}{|c|}{ Female $(\mathbf{n}=\mathbf{8})$} & \multirow[b]{2}{*}{$\begin{array}{l}\text { Variation } \\
(\%, 1 \times 11)\end{array}$} & \multirow[b]{2}{*}{$\begin{array}{c}\text { Difference } \\
\text { (95\% CI) } \\
\text { (Male vs Female) }\end{array}$} & \multirow[b]{2}{*}{$\begin{array}{c}\text { ES ( } 95 \% \mathrm{CI} \text { - } \\
\text { clssification) } \\
\text { (Male vs Female) }\end{array}$} \\
\hline & Week 1 & Week 11 & & Week 1 & Week 11 & & & \\
\hline$V_{\text {peak }}\left(k m \cdot h^{-1}\right)$ & $13.2 \pm 0.9$ & $14.3 \pm 0.9^{*}$ & $9.4 \pm 1.7 \#$ & $10.6 \pm 1.5$ & $11.5 \pm 1.5^{*}$ & $7.2 \pm 1.7 \#$ & $2.2(-4.0 ; 8.3)$ & $-0.03(-0.89 ; 0.85-$ trivial $)$ \\
\hline $\mathrm{t}_{\text {lim }}$ at $100 \% \mathrm{~V}_{\text {peak }}(\mathrm{min})$ & $6.3 \pm 0.7$ & $6.7 \pm 0.5$ & $6.7 \pm 17.6$ & $5.2 \pm 1.3$ & $5.6 \pm 1.6$ & $10.7 \pm 27.7$ & $-4.1(-28.9 ; 20.8)$ & $-0.18(-1.04 ; 0.77$ - trivial) \\
\hline $\mathrm{t}_{5 \mathrm{~km}}(\min )$ & $28.1 \pm 2.9$ & $24.5 \pm 2.4^{*}$ & $-13.0 \pm 1.8 \#$ & $36.9 \pm 5.7$ & $31.9 \pm 5.4^{*}$ & $-13.3 \pm 1.8 \#$ & $0.3(-6.2 ; 6.9)$ & $-0.10(-0.99 ; 1.35$ - trivial) \\
\hline rMSSD (ms) & $21.9 \pm 6.2$ & $28.7 \pm 11.0$ & $33.4 \pm 40.7$ & $24.5 \pm 10.3$ & $27.0 \pm 8.9$ & $13.9 \pm 21.4$ & $19.6(-15.9 ; 55.1)$ & $0.63(-0.85 ; 2.51$ - moderate $)$ \\
\hline
\end{tabular}

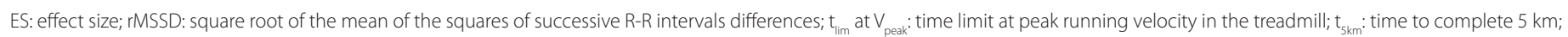
$V_{\text {peak }}$ : peak running velocity.

$* P<0.05$ Week 1 vs. Week 11.

\#Variation (means and standard error) was corrected by the baseline values (covariate) for these variables. 
in two different cycles. When the presence or not of PMS was applied in our analysis to control changes after the running training program, no influence in the results was observed ( $P>0.05$; unpublished data).

\section{Discussion}

The present study aimed to compare performance-related responses to an endurance running training program (i.e., with MICT and HIIT sessions) between untrained men and women. The main finding was that the responses to endurance running training showed to be similar between men and women. Percentage of change for men was "moderately" higher than for women for rMSSD, although statistically non-significant (confidence intervals crossing "0" for both ANOVA and ES). The non-difference between genders confirms our hypothesis.

These results are similar to the ones observed by de Prada et al.24 who showed that women and men improved similarly after a 16-week, 3 days/week, high-intensity interval training program in markers of aerobic fitness (e.g., oxygen uptake efficiency slope, $\mathrm{VO}_{2}$ at ventilatory threshold, $\mathrm{VE} / \mathrm{NCO}_{2}$ slope and $\dot{\mathrm{VO}}_{2 \text { max }}$ ). Metcalfe et al. ${ }^{11}$ investigated the differences between sedentary men and women with regards to $\dot{V}_{2 \max }$ changes after a 6-week reduced-exertion HIIT and found that both genders increased in similar magnitude this physiological variable.

While de Prada et al. ${ }^{24}$ and Metcalfe et al..$^{11}$ focused on physiological markers of aerobic fitness, our outcomes are indices of running performance, such as $V_{\text {peak }} t_{\lim }$ at $100 \% V_{\text {peak }}$ and $t_{5 \mathrm{~km}}$. The $V_{\text {peak }}$ is correlated with $\dot{V} O_{2 \max }{ }^{46}$ and in fact was previously associated with the occurrence of $\dot{\mathrm{V}}{ }_{2 \max }{ }^{47}$. In untrained and moderately-trained individuals, $\dot{\mathrm{V}} \mathrm{O}_{2 \max }$ is also a predictor of performance in endurance races (e.g., from $3 \mathrm{~km}$ to ultramarathons) $)^{46,47}$. Nevertheless, $V_{\text {peak }}$ would be a preferable predictor of performance in endurance events ${ }^{35,36,46}$, as it accounts for the interaction between $\dot{\mathrm{V}}_{2 \max }$ and running economy ${ }^{17}$.

The non-difference between genders could be because the HIIT planned was not intense enough to allow differences between women and men to be observed. Women have higher chances of presenting arterial desaturation when performing higher-intensity exercise ${ }^{19}$, and sprint exercises (i.e., higher than $100 \% \mathrm{~V}_{\text {peak }}$ ) can exacerbate differences between men and women in acute physiological responses, such as lower glycolysis rates in type I muscle fibers ${ }^{22}$ and lower blood lactate concentrations ${ }^{23}$. However, Astorino et a ${ }^{18}$ did not find differences between genders in the responses to 2-3 weeks of sprint exercise training (i.e., 4 bouts of Wingate test separated by 5 -min of active recovery) on $\dot{\mathrm{V}} \mathrm{O}_{2 \mathrm{max}}$ fatigability, substrate oxidation, and voluntary force production of the knee flexors and extensors, so this factor should not be influencing our findings.

Another aspect that could lead to different responses between men and women is the baseline performance differences between genders. Men had better results in the $t_{5 \mathrm{~km}}$ and $V_{\text {peak }}$ than women in this timepoint, which is expected if they are matched by their training levels (i.e., similar performance when compared to highly-trained runners of their gender) ${ }^{24}$. This is due to their physiological advantage compared to women. For instance, men present higher systolic volume and cardiac mass, greater lungs, and higher absolute and relative $\dot{V} O_{2 \max }{ }^{11,19,20}$. As men have a higher capacity to generate muscle power during physical efforts, they could have greater aerobic fitness benefits ${ }^{24}$. However, this was not observed in the present study and the assessed variables presented no differential progression with the training program. Similar results were found in other populations, such as young and physically active ${ }^{48}$, sedentary middle-aged ${ }^{9}$, and older healthy but sedentary populations ${ }^{49}$.

Our study did not find any significant gender-related differences in the rMSSD changes over the course of a running training program (confidence interval crossed " 0 " in the ANOVA and ES). However, the ES value (0.63) suggested a moderately greater improvement in men compared to women. The rMSSD is an HRV index related to cardiac autonomic function and changes in this variable represent adaptations in the parasympathetic activity ${ }^{29}$. Kiviniemi et al.$^{28}$ did not find any significant changes after 8 weeks of an aerobic training program in moderately active men and women for another parasympathetic index of HRV (SD1). However, the authors did not compared changes promoted by the training between men and women for SD1.

There are factors that could suggest some advantage for men compared to women in the changes in rMSSD, which may explain the greater ES we found in our study favorable to men (although not significant). For instance, the lower fitness level of women compared to men despite of the similar training status could have led women to a more exacerbated increase in sympathetic activity, particularly after high-intensity exercise ${ }^{28}$. This may attenuate women's long-term rMSSD response to aerobic exercise. Factors such as circulating hormone levels and higher odds of excessive heat stress after an acute session of exercise in women could have affected rMSSD responses to running training ${ }^{50,51}$. We did not perform the baseline and post-training assessment controlling by the phase of the menstrual cycle that women were; however, we monitored the presence or not of physical and emotional symptoms of pre-menstrual syndrome. With regards to the effect of menstrual cycle on aerobic variables, studies have reported no changes over the menstrual cycle on $\mathrm{V}_{\text {peak' }}, \dot{\mathrm{V}_{2 \max }}$ and other maximal and submaximal cardiorespiratory parameters ${ }^{52-55}$; however, other studies have found differences between luteal and follicular phases for these variables ${ }^{56,57}$.

We have important strengths in the study, such as matching male and female participants by relative fitness level in the baseline, as well as age and BMI. We also accounted for the baseline differences between men and women and the impact on training adaptations $8^{8,24}$. Nonetheless, we also have limitations, such as the small sample size for each group, as this study represents secondary data analysis from larger projects. Even though, we calculated a post hoc achieved power using G*Power 3.1 (Düsseldorf, Germany), and we found that both men and women groups were powered $(1-\beta>0.80)$ to detect training adaptations in $t_{5 k m}$ (i.e., main outcome). In an attempt of better controlling for type Il error in other outcomes, we provided magnitude of change analysis through between-group ES.

We did not control the specific phase of menstrual cycle that women were assessed for the baseline and post-training time points, but literature suggests that Vpeak, $\dot{V}_{2 \text { max }}$ and performance in shorter endurance-related distances are not affected by the phase of menstrual cycle ${ }^{52-55}$. To minimize individual perceptual changes in physical and emotional symptoms during the pre-menstrual phase, we assessed these perceptions in two menstrual cycles in a row and noted no influence in our findings of those with symptoms of pre-menstrual syndrome. 
Therefore, men and women responses to training were similar with regards to their running performance and cardiac autonomic function, with only a moderate ES for percentage changes in rMSSD for men compared to women. Regardless of the response to training, men presented higher endurance running performance than women did. $V_{\text {peak }}$ and its $t_{\text {lim }}$ can be applied in exercise settings for the prescription of moderate- to high-intensity running training with similar benefits independently of the gender.

\section{Acknowledgments}

This study was financed in part by the Coordenação de Aperfeiçoamento de Pessoal de Nível Superior - CAPES (Brazil) - Finance Code 001. In addition, the authors wish to thank Dr. Geraldo Nogueira from SportMed for assistance with cardiologic tests.

\section{Conflict of interest}

The authors do not declare a conflict of interest.

\section{Bibliography}

1. Garber CE, Blissmer B, Deschenes MR, Franklin BA, Lamonte MJ, Lee IM, Niemam, DC, Swain DP. American College of Sports Medicine position stand. Quantity and quality of exercise for developing and maintaining cardiorespiratory, musculoskeletal, and neuromotor fitness in apparently healthy adults: guidance for prescribing exercise. Med Sci Sports Exerc. 2011;43:1334-59.

2. van Dyck D, Cardon G, de Boudeaudhuij I, de Ridder L, Willem A. Who participates in running events? Socio-Demographic characteristics, psychosocial factors and barriers as correlates of non-participation- A pilot study in Belgium. Int J Environ Res Public Health. 2017;28:E1315.

3. Scheerder J, Breedveld K, Borgers J. Who Is Doing a Run with the Running Boom? In: Running across Europe. London. Palgrave Macmillan, 2015.

4. Cushman DM, Markert M, Rho M. Performance trends in large 10-km road running races in the United States. J Strength Cond Res. 2014;28:892-901.

5. Borgers J, Vos S, Scheerder J. Belgium Trends and Governance in Running. In: Running across Europe. London. Palgrave Macmillan, 2015.

6. Laursen P, Buchheit M. Science and application of high-intensity interval training: solutions to the programming puzzle. Champaign. Human Kinetics, 2018.

7. Buchheit M, Laursen PB. High-intensity interval training, solutions to the programming puzzle: Part l: cardiopulmonary emphasis. Sports Med. 2013;43:313-38.

8. Gibala MJ, Gillen JB, Percival ME. Physiological and health-related adaptations to lowvolume interval training: influences of nutrition and sex. Sports Med. 2014;44:S127-S37.

9. Alcaraz-Ibañez M, Rodríguez-Pérez M. Effects of resistance training on performance in previously trained endurance runners: A systematic review. J Sports Sci. 2018;36:613-29.

10. Boullosa D, Esteve-Lanao J, Casado A, Peyré-Tartaruga LA, Gomes da Rosa R, Del Coso J. Factors affecting training and physical performance in recreational endurance runners. Sports. 2020;8:35.

11. Metcalfe RS, Tardif N, Thompson D, Vollaard NB. Changes in aerobic capacity and glycaemic control in response to reduced-exertion high-intensity interval training (REHIT) are not different between sedentary men and women. Appl Physiol Nutr Metab. 2016;41:1117-23.

12. Lee DC, Sui X, Ortega FB, Kim YS, Church TS, Winett RA, Ekelud U, Katzmarzyk PT, Blair SN. Comparisons of leisure-time physical activity and cardiorespiratory fitness as predictors of all-cause mortality in men and women. Br J Sports Med. 2011;45:504-10.

13. da Silva DF, Ferraro ZM, Adamo KB, Machado FA. Endurance running training individually guided by HRV in untrained women. J Strength Cond Res. 2019;33:736-46.

14. Buchheit M, Chivot A, Parouty J, Mercier D, Al Haddad H, Laursen PB, Ahmaidi S. Monitoring endurance running performance using cardiac parasympathetic function. Eur J Appl Physiol. 2010;108:1153-67.

15. Esfarjani F, Laursen PB. Manipulating high-intensity interval training: Effects on $\mathrm{VO}_{2}$ the lactate threshold and $3000 \mathrm{~m}$ running performance in moderately trained males. J Sci Med Sport. 2007;10: 27-35.
16. Smith TP, Coombes JS, Geraghty DP. Optimizing high-intensity treadmill training using the running speed at maximal $\mathrm{O} 2$ uptake and the time for which this can be maintained. Eur J Appl Physiol. 2003;89:337-43.

17. Manoel FA, da Silva DF, Lima JRP, Machado FA. Peak velocity and its time limit are as good as the velocity associated with $\mathrm{VO}_{2 \mathrm{ma}} \times$ for training prescription in runners. Sports Med Int Open. 2017;1:E8-E15.

18. Kiviniemi AM, Tulppo MP, Eskelinen JJ, Savolainen AM, Kapanen J, Heinonen IH, Hautala AJ, Hannukainen JC, Kalliokoski K. Autonomic Function Predicts Fitness Response to Short-Term High-Intensity Interval Training. Med Sci Sports Exerc. 2014;46:1960-7.

19. Joyner MJ. Physiological limits to endurance exercise performance: influence of sex. J Physiol. 2017;1:2949-54.

20. Harms CA, McClaran SR, Nickele GA, Pegelow DF, Nelson WB, Dempsey JA. Exerciseinduced arterial hypoxaemia in healthy young women. J Appl Physiol (1985). 1998; $1: 619-28$.

21. Kanehisa H, Ikegawa S, Fukunaga T. Comparison of muscle cross-sectional area and strength between untrained women and men. Eur J Appl Physiol Occup Physiol. 1994; 68:148-54.

22. Esbjomsson-Liljedahl M, Sundberg CJ, Norman B, Jansson E. Metabolic response in type I and type II muscle fibers during a 30-s cycle sprint in men and women. J Appl Physiol. 1999;87:1326-32.

23. Esbjomsson-Liljedahl M, Bodin K, Jansson E. Smaller muscle ATP reduction in women than in men by repeated bouts of sprint exercise. J Appl Physiol. 2002;93:1075-83.

24. de Prada VG, Ortega JF, Palomo FM, Ramirez-Jimenez M, Moreno-Cabañas A, MoraRodriguez R. Women with metabolic syndrome show similar health benefits from high-intensity interval training than men. Plos One. 2019;14:1-17.

25. Keating SE, Johnson NA, Mielke Gl, Coombes JS. A systematic review and meta-analysis of interval training versus moderate-intensity continuous training on body adiposity. Obes Rev. 2017;18:943-64.

26. Peserico CS, Zagatto AM, Machado FA. Effects of endurance running training associated with photobiomodulation on 5-km performance and muscle soreness: A randomized placebo-controlled trial. Front Physiol. 2019;10:1-9.

27. Mourot L, Bouhaddi M, Tordi N, Rouillon JD, Regnard J. Short and long-term effects of a single bout of exercise on heart rate variability: comparison between constant and interval training exercises. Eur J Appl Physiol. 2004;92:508-17.

28. Kiviniemi AM, Hautala AJ, Kinnunen H, Nissila J, Virtanen P, Karjalainen J, Tulppo MP. Daily exercise prescription on the basis of $\mathrm{HR}$ variability among men and women. Med SciSports Exerc. 2010;42: 1355-63.

29. Buchheit M. Monitoring training status with HR measures: do all roads lead to Rome? Front Physiol. 2014;5:1-19.

30. Pereira LA, Flatt AA, Ramirez-Campillo R, Loturco I, Nakamura FY. Assessing shortened field-based heart-rate-variability-data acquisition in team-sport athletes. Int J Sports Physiol Perform. 2016;11:154-8.

31. Bloomfield DM, Magnano A, Bigger JT, Jr., Rivadeneira H, Parides M, Steinman RC. Comparison of spontaneous vs. metronome-guided breathing on assessment of vagal modulation using RR variability. Am J Physiol Heart Circ Physiol. 2001;280:H1145-50.

32. Williams DP, Jarczok MN, Ellis RJ, Hillecke TK, Thayer JF, Koenig J. Two-week test-retest reliability of the Polar ${ }^{\oplus}$ RS800CXTM to record heart rate variability. Clin Physiol Funct Imaging. 2017;37:776-81.

33. Cipryan L, Laursen PB, Plews DJ. Cardiac autonomic response following high-intensity running work-to-rest interval manipulation. Eur J Sport Sci. 2016;16:808-17.

34. Vesterinen V, Nummela A, Heikura I, Laine T, Hynynen E, Botella J, Hakkinen K. Individual endurance training prescription with heart rate variability. Med Sci Sports Exerc. 2016;48:1347-54.

35. Machado FA, Kravchychyn ACP, Peserico CS, da Silva DF, Mezzaroba PV. Incremental test design, peak 'aerobic' running speed and endurance performance in runners. J SciMed Sport. 2013;16:577-82.

36. Peserico CS, Zagatto A, Machado FA. Evaluation of the best-designed graded exercise test to assess peak treadmill speed. Int J Sports Med. 2015;36:729-34.

37. Tanaka H, Monahan KD, Seals DR. Age-predicted maximal heart rate revisited. J Am Coll Cardiol. 2001;37:153-6.

38. Borg GA. Psychophysical bases of perceived exertion. Med SciSports Exerc. 1982;14:377-81.

39. Jones AM, Doust JH. A 1\% treadmill grade most accurately reflects the energetic cost of outdoor running. J Sports Sci. 1996;14:321-7.

40. Kuipers $H$, Rietjens $G$, Verstappen F, Schoenmakers H, Hofman G. Effects of stage duration in incremental running tests on physiological variables. Int I Sports Med. 2003;24:486-91.

41. BillatVL, Hill DW, Pinoteau J, Petit B, Koralsztein JP. Effect of protocol on determination of velocity at $\mathrm{VO}_{2 \max }$ and on its time to exhaustion. Arch Physiol Biochem. 1996;104:313-21. 
42. American College of Obstetricians and Gynecologist (ACOG). Premenstrual syndrome. ACOG Practice Bulletin; 2000. 3 p.

43. Foster C. Monitoring training in athletes with reference to overtraining syndrome. Med SciSports Exerc. 1998;30:1164-8.

44. Cohen J. Statistical power analysis for the behavioral sciences. Hillsdale. Lawrence Erlbaum, 1988.

45. Hopkins WG, Marshall SW, Batterham AM, Hanin J. Progressive statistics for studies in sports medicine and exercise science. Med Sci Sports Exerc. 2009;41:3-12.

46. da Silva DF, Simões $H G$, Machado $F A$. $\vee O_{2 \max }$ versus $V_{\text {peak' }}$, what is the best predictor of running performances in middle-aged recreationally-trained runners? Sci Sports. 2015;30:e85-9.

47. McLaughlin JE, Howley ET, Bassett Jr DR, Thompson DL, Fitzhugh EC. Test of classic model for predicting endurance running performance. Med SciSports Exerc. 2010;42:991-7.

48. Astorino TA, Allen RP, Roberson DW, Jurancich M, Lewis R, McCarthy K, Trost E. Adaptations to high-intensity training are independent of gender. Eur J Appl Physiol. 2011;111:1279-86

49. Lepretre PM, Vogel T, Brechat PH, Dufour S, Richard R, Kaltenbach G, Berthel M, Lonsdorfer J. Impact of short-term aerobic interval training on maximal exercise in sedentary aged subjects. Int J Clin Pract. 2009;63:1472-78.
50. Charkoudian N, Joyner MJ. Physiologic considerations for exercise performance in women. Clin Chest Med. 2004;25:247-55.

51. Kenny GP, Jay O. Evidence of a greater onset threshold for sweating in females following intense exercise. Eur J Appl Physiol. 2007;101:487-93.

52. Burrows $M$, Bird SR. Velocity at $\mathrm{VO}_{2 \max }$ and peak treadmill velocity are not influenced within or across the phases of the menstrual cycle. Eur J Appl Physiol. 2005;93:575-80.

53. Janse de Jonge XA. Effects of the menstrual cycle on exercise performance. Sports Med. 2003;33:833-

54. Smekal G, von Duvillard SP, Frigo P, Tegelhofer T, Pokan R, Hofmann P, Tschan H, Baron R, Wonisch M, Renezeder K, Bachl N. Menstrual cycle: no effect on exercise cardiorespiratory variables or blood lactate concentration. Med SciSports Exerc. 2007;39:1098-106

55. Mattu AT, lannetta D, Maclnnis MJ, Doyle-Baker PK, Murias JM. Menstrual and oral contraceptive cycle phases do not affect submaximal and maximal exercise responses. Scand J Med Sci Sports. 2020;30:472-84.

56. Barba-Moreno L, Cupeiro R, Romero-Parra N, Janse de Jonge XAK, Peinado AB. Cardiorespiratory responses to endurance exercise over the menstrual cycle and with oral contraceptive use. J Strength Cond Res. 2019;10.1519/JSC.0000000000003447.

57. Goldsmith E, Glaister M. The effect of the menstrual cycle on running economy. J Sports Med Phys Fitness. 2020;60:610-17. 